\title{
Comparison of the insecticide susceptibilities of laboratory strains of Aedes aegypti and Aedes albopictus
}

\author{
Andrea Gómez ${ }^{1,2}$, Emilia Seccacini', Eduardo Zerba1,2, Susana Licastro'/1+ \\ ${ }^{1}$ Centro de Investigaciones de Plagas e Insecticidas, Instituto de Investigaciones Científicas y Técnicas para la Defensa, \\ Consejo Nacional de Investigaciones Científicas y Técnicas, Juan Bautista de La Salle 4397, B1603ALO Villa Martelli, Buenos Aires, Argentina \\ ${ }^{2}$ Instituto de Ingeniería y Investigación Ambiental-3iA, Universidad Nacional de General San Martín, Buenos Aires, Argentina
}

A susceptible strain of Aedes albopictus derived from the Gainesville strain (Florida, USA) was established in our laboratory. The larvicidal efficacies of the neurotoxic insecticides temephos, permethrin and the pure cis and trans-permethrin isomers and the microbial insecticide Bacillus thuringiensis israelensis (Bti) against Ae. albopictus were estimated and compared to a susceptible strain of Aedes aegypti. The larvicidal effect of insect growth regulator pyriproxyfen was also evaluated in both mosquito strains. The median lethal concentration/median emergency inhibition values for Ae. aegypti and Ae. albopictus, respectively, were: temephos, 3.058 and 6.632 ppb, permethrin, 3.143 and $4.933 \mathrm{ppb}$, cis-permethrin, 4.457 and $10.068 \mathrm{ppb}$, trans-permethrin, 1.510 and $3.883 \mathrm{ppb}$, Bti, 0.655 and $0.880 \mathrm{ppb}$ and pyriproxyfen, 0.00774 and $0.01642 \mathrm{ppb}$. Ae. albopictus was more tolerant than Ae. aegypti to all six larvicides evaluated. The order of susceptibility for Ae. aegypti was pyriproxyfen $>\mathrm{Bti}>$ trans-permethrin $>$ temephos $>$ permethrin $>$ cis-permethrin and for Ae. albopictus was pyriproxyfen $>\mathrm{Bti}>$ trans-permethrin $>$ permethrin $>$ temephos $>$ cis-permethrin. Because both species can be found together in common urban, suburban and rural breeding sites, the results of this work provide baseline data on the susceptibility of Ae. albopictus to insecticides commonly used for controlling Ae. aegypti in the field.

Key words: Aedes albopictus - Aedes aegypti - insecticide susceptibility

Dengue fever (DF) and dengue haemorrhagic fever are vector-borne diseases of public health importance in tropical, subtropical and temperate regions of the world (Gubler 1998). It is a popular belief that Aedes aegypti (Linnaeus) is the sole vector of the four distinct serotypes of dengue virus that causes the spectrum of disease symptoms collectively known as "dengue" (including DF, dengue haemorrhagic fever and dengue shock syndrome). However, other Aedes species, such as Aedes albopictus (Skuse), have been incriminated as DF vectors in epidemics in Southeast Asia and other parts of the world (Knudsen 1995) and could be responsible for the occurrence of these viruses in places where Ae. aegypti is absent (Shroyer 1986). Ae. albopictus is also a potential vector of several additional arboviruses, some of which have considerable medical importance, such as Chikungunya virus (Mangiafico 1971).

Ae. aegypti and Ae. albopictus are able to coexist in man-made containers in urban, suburban and rural areas (Vezzani \& Carbajo 2008). Additionally, Ae. albopictus larvae inhabit natural containers such as bromeliads, bamboo stumps and tree-holes close to human habitats

Financial support: Agencia Nacional de Promoción Científica y Tecnológica (MINCyT Argentina)

The research was conducted under a cooperative agreement with Chemotecnica SA (Argentina).

+ Corresponding author: slicastro1974@gmail.com

Received 31 March 2011

Accepted 31 August 2011 and can survive throughout a broad range of temperatures and relative humidity (RH) levels (Hawley 1988).

In North America, Ae. albopictus was first discovered in Texas (USA) in 1985 (Francy et al. 1990). In South America, it was discovered for the first time in Brazil during 1986 (Rai 1991). In Argentina, it was initially detected in Misiones near the Brazilian border, in early 1998 (Rossi et al. 1999, Schweigmann et al. 2004).

The continuous expansion of the geographic range of Ae. albopictus in Latin America, including Argentina, the recent findings regarding its vector potential (Mitchell et al. 1987) and the observations made indicating a competitive advantage for Ae. albopictus over Ae. aegypti (Braks et al. 2004), have increased the public awareness of this mosquito and the attempts to control it.

In the absence of a dengue vaccine, controlling dengue vectors is regarded as essential in preventing epidemics. The application of larvicides to containers that cannot be eliminated is still considered a priority by control programmes. However, this activity is both labour intensive and time consuming and not all containers can be treated because there are certain locations in and around urban areas that offer permanent breeding sites. In addition, the continuous application of insecticides in vector control strategies can result in the development of insecticide resistance.

To contribute to the knowledge on the susceptibility of dengue vectors to insecticides, we determined a baseline susceptibility of laboratory strains of Ae. aegypti and Ae. albopictus larvae to the insecticides commonly used in Argentina for vector control. This information will be valuable in the implementation of further resistance monitoring programmes. According to our past 
experience, the baseline susceptibility to insecticides was similar for laboratory and field strains of Ae. aegyp$t i$ in areas without insecticide treatments (Seccacini et al. 2008b, Albrieu Llinás et al. 2010). The results of this work will allow us to determine the most effective compound for the less susceptible mosquito species and to suggest the best strategy control authorities if both species coexist in urban and periurban breeding containers.

Susceptible strains of Ae. aegypti (derived from the Rockefeller strain from Venezuela) and Ae. albopictus (derived from the strain from Gainesville, FL, USA) were reared at $25 \pm 2^{\circ} \mathrm{C}$ at $80-90 \% \mathrm{RH}$ and with a photoperiod of 12:12 h. Larvae of both species were fed on a mixture of rabbit pellets and yeast and were used for the bioassays according to the methods of previous studies (Lucia et. al. 2007).

Pyriproxyfen (97.8\%) (China Kelinon Agrochemical Co, Ltd, China), temephos (90\%) (Ningguo Jiahua Chemistry Co, Ltd, China) and Bti [Bacillus thuringiensis israelensis, Bactivec ${ }^{\circledR}$ - 1200 International Toxic Units (ITU)/mg, Valent BioSciences, USA] were used as insecticides. Technical grade permethrin (cis:trans mixture 1:1), cis-permethrin and trans-permethrin were provided by Chemotecnica SA, Argentina.

The test concentrations of all insecticides, except temephos and $B t i$, were prepared by successive dilutions of $1 \mathrm{mg} / \mathrm{mL}$ acetone solutions. Temephos was diluted in absolute ethanol and Bti was diluted in water. All solvents used were for analysis (Merck, Germany).

The larvicidal bioassay was performed according to a protocol previously used in our laboratory (Bisset et al. 2005). One millilitre of the insecticide solution to be tested was added to $224 \mathrm{~mL}$ of water in a $500 \mathrm{~mL}$ plastic jar, which was shaken lightly to ensure a homogeneous test solution. Then, 20 late third or early forth instar Ae. ae- gypti or Ae. albopictus larvae previously acclimated for $2-3 \mathrm{~h}$ in $25 \mathrm{~mL}$ of water were added to the jar. Five different concentrations of each insecticide were tested and untreated cups were used as a control. Each concentration was replicated three-five times. No food was offered to the larvae except in the pyriproxyfen assay, in which approximately $100 \mathrm{mg}$ of rabbit pellets were added to each jar. All bioassays were conducted in a regulated chamber $\left(25 \pm 2^{\circ} \mathrm{C}, 80-90 \% \mathrm{RH}\right.$ and $12: 12 \mathrm{~h}$ photoperiod) and larvae mortality was recorded after $24 \mathrm{~h}$ of exposure to temephos, Bti, permethrin and the cis/trans isomers. As in previous studies (Seccacini et al. 2008a) of pyriproxyfen, the jars were examined daily and cumulative larval and pupal mortality and adult emergence were recorded until adult emergence was complete in all of the control jars.

Dose-mortality data from each pool were subjected to probit analysis (Litchfield \& Wilcoxon 1949). The $50 \%$ and $95 \%$ lethal concentrations $\left(\mathrm{LC}_{50}\right.$ and $\left.\mathrm{LC}_{95}\right)$ with the corresponding confidence limits were obtained using PoloPlus 2.0 (LeOra Software, USA) and were expressed as the final concentration in parts per billion. For pyriproxyfen, the effective concentration to inhibit adult emergence by $50 \%\left(\mathrm{EI}_{50}\right)$ observed on the day all of the control mosquitoes emerged as adults was calculated. The values of $\mathrm{LC}_{50}$ and $\mathrm{EI}_{50}$ were adjusted for the mortality of the controls (Mulla et al. 1974) and were considered to be significantly different if the $95 \%$ confidence intervals (CI) did not overlap (Robertson \& Preisler 1992). A tolerance index is defined as the ratio between the $\mathrm{LC}_{50}$ or the $\mathrm{EI}_{50}$ values for Ae. albopictus and those for Ae. aegypti was calculated for each insecticide assayed. Table shows the larvae mortality data for $A e$. aegypti and Ae. albopictus expressed as $\mathrm{LC}_{50} / \mathrm{EI}_{50}$ and $\mathrm{LC}_{95} / \mathrm{EI}_{95}$ with the corresponding CIs and the tolerance index between species. Pyriproxyfen was the most ef-

TABLE

Comparative susceptibility of Aedes aegypti and Aedes albopictus to larvicides used in Argentina

\begin{tabular}{|c|c|c|c|c|c|}
\hline \multirow[b]{2}{*}{ Insecticide } & \multicolumn{2}{|c|}{ Ae. aegypti } & \multicolumn{2}{|c|}{ Ae. albopictus } & \multirow[b]{2}{*}{ Tolerance index } \\
\hline & $\begin{array}{c}\mathrm{LC}_{50} \\
(95 \% \mathrm{CI}) \mathrm{pbb}\end{array}$ & $\begin{array}{c}\mathrm{LC}_{95} \\
(95 \% \mathrm{CI}) \mathrm{pbb}\end{array}$ & $\begin{array}{c}\mathrm{LC}_{50} \\
(95 \% \mathrm{CI}) \mathrm{pbb}\end{array}$ & $\begin{array}{c}\mathrm{LC}_{95} \\
(95 \% \mathrm{CI}) \mathrm{pbb}\end{array}$ & \\
\hline Temephos & $\begin{array}{c}3.058 \\
(2.533-3746)\end{array}$ & $\begin{array}{c}6.546 \\
(4.998-11.126)\end{array}$ & $\begin{array}{c}6.632 \\
(5.975-7.339)\end{array}$ & $\begin{array}{c}10.746 \\
(9.352-13.543)\end{array}$ & $\begin{array}{c}2.169 \\
(1.853-2.540)\end{array}$ \\
\hline Permethrin & $\begin{array}{c}3.143 \\
(2.609-3.703)\end{array}$ & $\begin{array}{c}9.381 \\
(7.330-13.827)\end{array}$ & $\begin{array}{c}4.933 \\
(4.080-6.033)\end{array}$ & $\begin{array}{c}13.578 \\
(10.121-22.239)\end{array}$ & $\begin{array}{c}1.569 \\
(1.249-1.972)\end{array}$ \\
\hline Cis-permethrin & $\begin{array}{c}4.457 \\
(3.984-4.992)\end{array}$ & $\begin{array}{c}10.015 \\
(8.419-12.819)\end{array}$ & $\begin{array}{c}10.068 \\
(8.888-11.407)\end{array}$ & $\begin{array}{c}24.942 \\
(20.654-32.480)\end{array}$ & $\begin{array}{c}2.260 \\
(1.910-2.674)\end{array}$ \\
\hline Trans-permethrin & $\begin{array}{c}1.510 \\
(1.233-1.853)\end{array}$ & $\begin{array}{c}5.202 \\
(3.777-8.752)\end{array}$ & $\begin{array}{c}3.883 \\
(3.432-4.384)\end{array}$ & $\begin{array}{c}7.010 \\
(5.901-9.428)\end{array}$ & $\begin{array}{c}2.572 \\
(2.180-3.035)\end{array}$ \\
\hline$B t i$ & $\begin{array}{c}0.655 \\
(0.528-0.796)\end{array}$ & $\begin{array}{c}1.364 \\
(1.053-2.391)\end{array}$ & $\begin{array}{c}0.880 \\
(0.765-1.014)\end{array}$ & $\begin{array}{c}1.919 \\
(1.565-2.640)\end{array}$ & $\begin{array}{c}1.267 \\
(1.095-1.467)\end{array}$ \\
\hline Pyriproxyfen $^{a}$ & $\begin{array}{c}0.008 \\
(0.005-0.011)\end{array}$ & $\begin{array}{c}0.067 \\
(0.040-0.148)\end{array}$ & $\begin{array}{c}0.016 \\
(0.008-0.032)\end{array}$ & $\begin{array}{c}0.217 \\
(0.089-1.219)\end{array}$ & $\begin{array}{c}2.122 \\
(1.209-3.725)\end{array}$ \\
\hline
\end{tabular}

$a$ : the effective concentration for pyriproxyfen is measured as adult emergence inhibition $\left(\mathrm{EI}_{50} / \mathrm{EI}_{95}\right)$ not as lethal concentration $\left(\mathrm{LC}_{50} / \mathrm{LC}_{95}\right)$. Bti: Bacillus thuringiensis israelensis; CI: confidence interval. 
fective insecticide against Ae. aegypti and Ae. albopictus. A tolerance index is defined as the ratio between the $\mathrm{LC}_{50}$ or the $\mathrm{EI}_{50}$ values for Ae. albopictus, and those for Ae. aegypti was calculated for each insecticide assayed that of cis-permethrin $\left(\mathrm{LC}_{50}=4.457\right.$ and $\left.10.068 \mathrm{ppb}\right)$, the less active isomer of permethrin. Bti was also effective, with $\mathrm{LC}_{50}=0.655$ and $0.880 \mathrm{ppb}$ for Ae. aegypti and Ae. albopictus, respectively, followed by trans-permethrin $\left(\mathrm{LC}_{50}=1.510\right.$ and $3.883 \mathrm{ppb}$, respectively), which was more effective than permethrin (cis:trans 1:1 mixture with 3.143 and $4.933 \mathrm{ppb}$, respectively) and temephos (3.058 and $6.632 \mathrm{ppb}$, respectively).

For temephos, the mortality data we obtained for $A e$. albopictus (Table) were similar to the data obtained by other authors (Ali et al. 1995, Romi et al. 2003, Ponlawat et al. 2005), but for permethrin there were differences that could be due to the fact that in most of the cases the exact composition of permethrin (ratio of cis/trans isomers) is unknown (Sulaiman et al. 1991, Ali et al. 1995). We found that for both mosquito species transpermethrin was more effective than the 1:1 cis-trans mixture and cis-permethrin alone. These results are in agreement with the results obtained by Pap et al. (1996), who found that the trans isomers of some pyrethroids were more active than the cis isomers against Aedes mosquitoes. For mammals and most insect species, it has been reported that the cis isomer is more active than the trans isomer (Naumann 1990), because the trans isomer is metabolised faster by hydrolytic esterases (Perry et al. 1998). As can be seen in Table, the inverse situation was observed for Ae. aegypti and Ae. albopictus.

The small difference observed between Bti and pyriproxyfen in both mosquito species (Table) could be related to the particular mode of action of these larvicides. Bti endotoxin acts on the midgut epithelium, which is presumably similar in these two species. Pyriproxyfen is a mimic of a juvenile hormone that regulates metamorphosis. We also found a higher toxicity value for $B t i$ than other authors have (Ali et al. 1995, Duque \& Navarro-Silva 2005). When Bti is used, the active ingredient concentration is expressed as ITU compared to a known standard. Our laboratory found differences between the nominal and real ITU values for Bti formulations of different origins (unpublished observations). Larvae mortality is strongly dependent on the Bti formulation, being affected by factors such as the bacteria strain, way of fermentation and shell stability. An important factor affecting the performance of a particular Bti formulation is time elapsed since it was manufactured.

Table also shows the tolerance index for Ae. albopictus relative to Ae. aegypti. The susceptibilities of Ae. aegypti and Ae. albopictus to insecticides were different, but based on the CIs, these differences were only significant $(\mathrm{p}<0.05)$ for the neurotoxic insecticides (temephos, permethrin, cis-permethrin and trans-permethrin), but not for pyriproxyfen and $B t i$, most likely due to its different mode of action.

There is very little published information on the susceptibilities to insecticides of Ae. albopictus compared to Ae. aegypti under laboratory conditions. A review of insecticide resistance in dengue vectors revealed that there is a great deal of information regarding the insecticide susceptibility of Ae. aegypti; some on information on the susceptibility of Ae. albopictus and few studies that have compared both species (Ranson et al. 2010). Another fact to consider is that there is no available reference strain for Ae. albopictus. The reference strain for Ae. aegypti in most laboratories is the Rockefeller strain or the Bora-Bora strain. However, almost all the studies on Ae. albopictus use a local field strain that was collected and reared in the laboratory for different periods of time and then the most susceptible strain is taken as the reference. In our case, we used the Gainesville strain, which has been reared in the laboratory since 1992 and is strongly believed to be susceptible.

Based on our results, we conclude that, for laboratory strains, Ae. albopictus is more tolerant than Ae. aegypti to the six compounds studied, but this difference was only significant for neurotoxic insecticides. The most effective insecticide was pyriproxyfen and trans-permethrin was more effective than the cis-trans mixture or the cis isomer. $\mathrm{LC}_{50}$ values obtained in the laboratory are useful to compare the insecticidal effects between insect strains, although it is known that the field concentrations used for control strategies are higher than the $\mathrm{LC}_{50}$ values obtained in the laboratory.

For vector control strategies, the Ministry of Health of Argentina currently uses temephos and Bti as larvicides and cis-permethrin as an adulticide. New formulations based on pyriproxyfen and permethrin are needed in Argentina.

This comparative study of the susceptibility of Ae. aegypti and Ae. albopictus to larvicides with different modes of action under laboratory conditions could provide baseline susceptibility data for the insecticides used in vector control programmes and these data could be useful for further studies on field strains and in the monitoring of resistance. Ae. aegypti and, to an increasing extent, Ae. albopictus are species that do not respect country borders and because both mosquito species can be found in the same man-made containers in urban and periurban areas, information on the insecticide susceptibilities of both species could help to improve future control activities.

\section{REFERENCES}

Albrieu Llinás G, Seccacini E, Gardenal CN, Licastro S 2010. Current resistance status to temephos in Aedes aegypti from different regions of Argentina. Mem Inst Oswaldo Cruz 105: 113-116.

Ali A, Nayar JK, Xue RD 1995. Comparative toxicity of selected larvicides and insect growth regulators to a Florida laboratory population of Ae. albopictus. J Am Mosq Control Assoc 11: 72-76.

Bisset J, Blanco S, Braga I, Coto H, Masuh H, Moncayo A, Nathan M, Orellano P, Vázquez J, Zerba E 2005. Protocolo para determinar la susceptibilidad o resistencia a insecticidas de mosquitos de la especie Aedes aegypti. Documento propuesto por la Red Latinoamericana de Control de Vectores, Fundación Mundo Sano, Buenos Aires, 13 pp.

Braks MAH, Honório NA, Lounibos LP, Lourenço-de-Oliveira R, Juliano SA 2004. Interspecific competition between two invasive species of container mosquitoes, Aedes aegypti and Aedes albopictus (Diptera: Culicidae), in Brazil. Ann Entomol Soc Am 97: 130-139. 
Duque JE, Navarro-Silva MA 2005. Susceptibilidad de larvas de Aedes (Stegomyia) albopictus (Diptera: Culicidae) de São Paulo, Brasil al Bacillus thuringiensis var israelensis H-14. Rev Colomb Entomol 31: 199-201.

Francy DB, Moore CG, Eliason DA 1990. Past, present and future of Aedes albopictus in the United States. J Am Mosq Control Assoc 6: 127-132.

Gubler DJ 1998. Dengue and dengue hemorrhagic fever. Clin Microbiol 11: 480-496.

Hawley WA 1988. The biology of Aedes albopictus. J Am Mosq Control Assoc 4: 1-39.

Knudsen AB 1995. Global distribution and continuing spread of Aedes albopictus. Parassitologia 37: 91-97.

Litchfield JT Jr, Wilcoxon F 1949. A simplified method of evaluating dose-effect experiments. J Pharmacol Exp Ther 96: 99-113.

Lucia A, Gonzalez P, Seccacini E, Licastro S, Zerba E, Masuh H 2007. Chemical composition and larvicidal effect of Eucalyptus grandis essential oil, turpentine oil and its major components on Aedes aegypti larvae (Diptera: Culicidae). J Am Mosq Control Assoc 23: 299-303.

Mangiafico JA 1971. Chikungunya virus infection and transmission in five species of mosquito. Am J Trop Med Hyg 20: 642-645.

Mitchell CJ, Miller BR, Gubler DJ 1987. Vector competence of Aedes albopictus from Houston, Houston, Texas, for dengue serotypes 1 to 4, yellow fever and Ross River viruses. J Am Mosq Control Assoc 3: 460-465.

Mulla MS 1974. Laboratory and field evaluation of insect growth regulators against mosquitoes. Proc \& Papers Calif Mosq Control Assoc 42: 175-176.

Naumann K 1990. Chemistry of plant protection. In G Haug, H Hoffmann (eds.), Synthetic pyrethroid insecticides: structures and properties, IV vol., Springer-Verlag, Berlin Heidelberg, 241 pp.

Pap L, Kelemen M, Tóth A, Székely I, Brtók B 1996. The synthetic isomers II. Biological activity. J Environ Sci Health B 31: 527-543.

Perry AS, Yamamoto I, Ishaaya I, Perry RY 1998. Insecticides in agriculture and environment: retrospects and prospects, SpringerVerlag, Berlin Heidelberg, 261 pp.
Ponlawat A, Scott JG, Harrington LC 2005. Insecticide susceptibility of Aedes aegypti and Aedes albopictus across Thailand. J Med Entomol 42: 821-825.

Rai KS 1991. Aedes albopictus in the Americas. Ann Rev Entomol 36: $459-484$.

Ranson H, Burhani J, Lumjuan N, Black IV WC 2010. Insecticide resistance in dengue vectors. TropIKA.net [serial on the Internet]. [cited: 2011 July 05], 1 (1) pp. 1-12. Available from: journal.tropika.net/scielo.php?script $=$ sci_arttext\&pid $=$ S2078$86062010000100003 \& \operatorname{lng}=$ en\&nrm=iso.

Robertson JL, Preisler HK 1992. Pesticide bioassays with arthropods, CRC Press, Boca Raton, 144 pp.

Romi R, Toma L, Severini F, Di Luca M 2003. Susceptibility of Italian population of Aedes albopictus to temephos and to other insecticides. J Am Mosq Control Assoc 19: 419-423.

Rossi GC, Pascual NT, Krsticevic FJ 1999. First record of Aedes albopictus (Skuse) from Argentina. J Am Mosq Control Assoc 15: 422-423.

Schweigmann N, Vezzani D, Orellano P, Kuruc J, Boffi R 2004. Aedes albopictus in an area of Misiones, Argentina. Rev Saude Publica 38: 136-138.

Seccacini E, Lucia A, Harburguer L, Zerba E, Licastro S, Masuh H 2008a. Effectiveness of pyriproxyfen and diflubenzuron formulations as larvicides against Aedes aegypti. J Am Mosq Control Assoc 24: 398-403.

Seccacini E, Lucia A, Zerba E, Licastro S, Masuh H 2008b. Aedes aegypti: resistance to temephos in Argentina. J Am Mosq Control Assoc 24: 608-609.

Shroyer DA 1986. Aedes albopictus and arboviruses: a concise review of the literature. J Am Mosq Control Assoc 2: 424-428.

Sulaiman S, Omar B, Jeffery J, Busparani V 1991. Evaluation of pyrethroids lamda-cyhalothrin, deltamethrin and permethrin against Aedes albopictus in the laboratory. J Am Mosq Control Assoc 7: 322-323.

Vezzani D, Carbajo AE 2008. Aedes aegypti, Aedes albopictus and dengue in Argentina: current knowledge and future directions. Mem Inst Oswaldo Cruz 103: 66-74. 